Such being the state of the patient at the time of her admission, it was determined to search for a metal which might have some influence on her symptoms (metalloscopy). The following observations were therefore made.

On Feb. 21st, at 10.30 A.M., three pieces of gold (a sovereign and two half sovereigns) were applied in a slanting direction to the left temple. The sovereign was the highest of the three coins, and was situated just above the outer end of the eyebrow. For some time there was no alteration in her condition, but in twenty minutes she had a feeling as if " something living " was moving from temple to temple. Sensation and the sense of pain now extended beyond the middle line of the forehead as far to the left as the sovereign, but no further, while the sensation on the right side remained perfect as before. In twenty-three minutes she could distinguish the colour of violet with the left eye, but green she still called black. The sight of the right eye was not affected, but she complained of frontal headache, sighed frequently, and had spasmodic jerkings of the head. On removal of the coins, under which the anæsthesia was un. affected, the headache and jerkings disappeared. At 3 P.M., when she was again seen, the alteration in the symptoms above mentioned still persisted.

At this time a large magnet was held over the left forearm, at a distance of about half an inch from the surface. In half a minute sensation began to return to the left forearm, and within five minutes there was complete return of sensation and sense of pain to the whole of the left side of the body, but the whole of the right side had become completely hemianæsthetic and analgesic. The left eye continued in the same state as regards the colour-blindness as before the observation, but with the right green appeared to her black. The magnet was next held over the right forearm, at the distance of half an inch from it, and in two minutes and a half sensation had returned to the whole of the right side of the body ; but, contrary to expectation, the left side did not again become anæsthetic, so that sensation was now perfect over the whole body. The colour-blindness remained as before the last observation.

Next day (Feb. 22nd) she was in the same state-that is, sensation was perfect all over; with the left eye she could distinguish all colours, while with the right she mistook green for black. The magnet was now placed within half an inch of the left forearm, and in three minutes the whole of the left side became anzesthetic and analgesic, including the mucous membrane of the left eye (which could be touched without the patient feeling it at all), left side of the nostril, mouth, and tongue, the sense of taste being likewise gone on this side. The colour-blindness did not, however, reappear on the left side, although with the right eye she mistook violet for black. The left ovary continued tender. The magnet was next held close to the right forearm, and in three minutes sensation had disappeared from the right side of the body, but there was no transference of the sensation to the other side, so that the whole body was now anæsthetic, including the mucous membranes, and she had entirely lost the sense of taste. When in this state a circular piece of lead, four inches in diameter, was fastened to the right forearm, and in one minute sensation was restored to both sides of the body, and there was no colour-blindness with either eye, but the left ovarialgia persisted. A piece of tin of the same size and shape was next applied over the left arm without her knowing of the change of metal, but in seven minutes, there being no alteration in the symptoms, the lead plate was substituted, but was removed in five minutes, as it had no effect. The magnet was then held over the left forearm, and in a minute there was anæsthesia and analgesia of the right side of the body, but on transferring the magnet to the right side, the anresthesia and analgesia were immediately transferred to the left side. She could now distinguish all colours with the right eye, but with the left she called green black.

At a meeting of the Medico-Chirurgical Society on Feb. 28th, before a large number of the profession, the patient was blindfolded, and the following additional observations were made: - (1) The ordinary magnet with keeper on had no effect, though used for at least ten minutes. (2) A large electro-magnet was employed by my colleague Professor McKendrick. So long as the current was not allowed to pass, there was no result, but in three minutes after it was turned on, without her being made aware of it, the sensation returned to the left side of the body, while the right became anæesthetic and analgesic, being the reverse of her state before the electro-magnet was used.
On Tuesday, March 4th, with the co-operation of Drs. McKendrick, Ramsay, and Service, and the patient being blindfolded, a solenoid was placed on the little finger of the left (anresthetic) side. For seven minutes it was not connected with the battery (Stöhrer's) which was placed underneath the bed, with an assistant in charge of it, and there was no result. The connexion was then made (and in such a way that it was absolutely impossible for the patient to know what was being done), eight cells being in use, and in seven minutes the left side became resthesic, and the right anæsthetic.

The temperature was compared simultaneously on the two sides, before the transference, by means of Lombard's delicate thermo-electric apparatus (which, however, does not give the difference in degrees), and it was found that the right side was the warmer. The same result was obtained after the transference of the anzesthesia to the right side, as well as on the following day, the condition of the patient in the interval remaining the same as after the employment of the solenoid.

On March 19th internal metallo-therapy (Burqism) was resorted to--that is, the internal administration of the metal which, applied externally, caused a transference of the phenomena. Lead being one of the metals in question in this case, the acetate of lead in doses of two grains was given in pill thrice daily.

Next day (March 20th) she had a fit which lasted for an hour, and on the afternoon of the $25 \mathrm{th}$, while sewing, she noticed that sensation had returned to the left side. The left ovarian tenderness was now found to be diminished, though not gone, but the colour-blindness, as regards violet, remained.

The treatment was continued up to the time of her leaving the hospital on April 5th. While under observation she had all along been very troublesome, and she finally left after having quarrelled with one of the " scrubbers." At this time she was in the same state as on March 25th.

The symptoms observed in this patient corroborate in the main those recorded by Charcot, with some exceptions, however. Thus (1) she was susceptible to more than one metalto lead and partially to gold; (2) after the anosthesia was transferred to the right side with a magnet, on using it on the right side, sensation returned to that side, but did not leave the left; (3) sensation being perfect on both sides, the magnet was applied to the left arm, and sensation disappeared on that side. Then, on applying it to the right arm, the right side became anæsthetic, but the left side remained ancesthetic too, so that the whole body was now anzesthetic, and there was tenderness (though not so marked) over the right as well as over the left ovary, indeed more or less over most of the abdomen ; (4) on applying lead to the right arm, the whole body being anæsthetic, sensation returned to both sides.

I purposely abstain from any remark upon this case further than to say that, extraordinary as the symptoms undoubtedly were, I thoroughly satisfied myself that they were real, and not imaginary, and that deception on the part of the patient was altogether out of the question.

Glasgow.

\section{CASE OF TRAUMATIC TETANUS, TREATED WITH THE HYPODERMIC INJECTION \\ OF ATROPIA; AMPUTATION OF GREAT TOE; RECOVERY.}

BY SuRgeon D. H. CULLIMORE, F.R.C.S.I., \&C., EX-RESIDENCY SURGEON AT THE COURT OF THE KING OF BURMAH

IN April, 1875, when the highest temperature in the shade was $98^{\circ} \mathrm{F}$, with a great diurnal variation, the rainy season having just set in, a Lascar, a camp follower, was admitted into the hospital for details at Rangoon, Burmah, suffering from a lacerated contused wound of the great toe, inflicted some three days previously by the tread of a horse. The patient (a powerful muscular man, aged twenty-eight years) was confined to bed, and a rice poultice, medicated with laudanum, applied for two days, when, no improvement taking place, and the condition and seat of the injury being such as is frequently followed by tetanus, the toe was 
amputated, with the object of removing what I was afraid might become the exciting cause of that disease, when, somewhat to my surprise, in about fifty hours after the performance of the operation, the symptoms of tetanus became manifest-first, by yawning and listlessness; secondly, by stiffness of the muscles of the neck and the abdomen, accompanied by the usual expression of face; and, lastly, and fater on, by spasmodic contraction of the abdominal muscles and opisthotonos, which latter continued for about six hours on the fourth day from the inception of the disease.

As this was the fourth case that came under my notice in the space of six months, one of which was treated with chloral, and the others with hypodermic injection of atropia in combination with morphia, and as all three terminated fatally between the ninth and the twelfth day, I felt convinced that chloral would prove a failure, and, judging from the physiological effect of morphia and atropia, which is the reverse of each other, at least in so far as their action on the pupil is observed, I determined to try atropia alone, more with the object of noting its action than with any but a vague hope that it might be the means of preventing a fatal issue. On the first appearance of the symptoms onesixtieth of a grain of atropia was injected hypodermically over the dorsal spinal region, and was repeated three times daily. On the morning of the second day one-fortieth of a grain was injected every four hours, and continued for six successive days, till the spasms had entirely ceased, and the stiffness disappeared from all but the muscles of the neck and face, which, as they were the first to become affected, continued longest under the influence of the disease. On the eighth and ninth days the dose was reduced to onesixtieth of a grain twice a day, and subsequently reduced to one-sixtieth of a grain at night for a further period of two days, ending on the evening of the eleventh day from the commencement of the disease, when the patient, though not yet cured, was well out of danger, and in a fair way to recovery.

I should have mentioned that the bowels were constipated throughout, and were acted upon by four grains of calomel with forty grains of compound jalap powder, administered every other day, and that after each evacuation the patient invariably expressed himself "much lighter" and relieved.

Under the influence of tonics and nourishing diet, with an occasional purgative, such progress was made that on the twenty-sixth day from his admission into hospital, and on the twenty-first from the manifestation of tetanic symptoms, the man was discharged. During his stay in hospital, and within the space of nine days, two grains of atropia were introduced into his system, which caused neither dilatation of the pupil nor any continued increase of temperature; in fact, there was no ascertainable physiological action, with, perhaps, the exception of drowsiness and slight occasional hyperæsthesia of the surface, which I am now more inclined to connect with the disease than the remedy.

Though this case occurred so long ago, the facts may be relied upon, as the notes were taken at the time, but not published from want of leisure.

Remarks. - The points illustrated by this case are :-

1. That tetanus-i, e., a series of reflex phenomena depending upon an over-excited or congested state of the brain, the spinal cord, and their membranes-is capable of being relieved, or even cured, by atropia, when administered in comparatively small doses, extended over a certain period of time according to the severity of the symptoms; though we know from the experience and experiments of Drs. Harley, Fraser, and others, that when given to its full physiological effect it produces excitement and congestion of the cord, followed by the usual reflex results, as jactitation, muscular spasm, and convulsive fits.

2. That the administration of the medicine was not followed by any of the easily recognisable symptoms of the drug (two grains of which has caused the death of a healthy adult when given in one dose), proving both the tolerance induced by the disease, and, perhaps, also illustrating the homoopathic theory or formula, sine the infinitesimal system of dosage.

3. That amputation of the injured part, recommended so strongly by Larrey and others, even after the supervention of tetanus, though it may perhaps help to lessen the severity of the disease, does not act as a prophylactic, and should, I think, never be had recourse to after the symptoms have declared themselves. It would then be injurious, for the peripheral irritation would have becom central, and inde- pendently dynamic. For the same reason, the division of nerves should not be resorted to. In two cases where I examined the nerves after death I failed to perceive that they differed in any way from those of the opposite side. In one of these there was slight congestion of the membranes and a softening of the cord in the lumbar region, and in the other a peculiar cloudiness of the cord, which may, however, have been due to post-mortem changes. Yet it is certain that there is some lesion, though in every case we may not be able to perceive it. This lesion should be looked for in that portion of the spinal cord with which the nerves from the affected part first communicate.

4. If the line of treatment adopted in this case should be found beneficial in others of the same disease, I would sug. gest that it might be extended, with such modifications as may be necessary, to the treatment of such allied diseases as epilepsy, puerperal convulsions, and hydrophobia.

Devonshire-street, Portland-place, $w$.

\section{CASE OF}

\section{SUPPOSED DEAF-MUTISM ; EUSTACHIAN CLOSURE ; MOIST CATARRH OF TYMPANUM ; RECOVERY.}

\section{By T. WEMYSS BOGG, M.B., M.R.C.P. LoND.}

IN August last, at the Christ Church Infant Nursery, in this town, my attention was directed to an older child, who was stated to be an inmate because of being deaf and dumb. Never having inspected the ears of a deaf-mute, I asked permission to examine hers, and on doing so a few days later I learned that the deaf-mutism was not absolute, and obtained the following history.

Jemima B_-, aged five years; had two maternal uncles who became stone deaf; had scarlet fever at eleven months: no otorrhœa, no convulsions, but has been deaf ever since. Was unable to go to school, or to hear passing vehicles.

August 13th, 1878. - Child hears when spoken to in a loud voice; puts a watch to her ears; smiles when a tuning-fork is placed at her right ear. Tries to imitate some sounds, and can say imperfectly about twenty words-viz., Freddy, Johnny, dada, mamma, Bob, get away, leave off, one, two, three, four, five. Cannot ask for anything by name; palate not cleft. Right membrana tympani entire, rather opaque cone of light visible. Left membrana the same, partly hidden by wax. On learning these facts, I concluded that treatment with Allen's nasal bag would either relieve or cure her deafness, and applied it to her nostrils several times every day, or every other day, from Aug. 14th to Sept. 13th, afterwards less frequently. After the first application she appeared to hear my voice better.

16th. - Her mother says she certainly hears better. Syringed left ear and removed a considerable quantity of hard wax. Several enlarged vessels seen on malleus; moist sound in ear heard on using Allen's nasal bag. She heard the nurse speak to her this morning.

17th.-While lying in bed this morning, lifted up her finger as a sign to listen while a cart was passing.

2lst. - Seems to hear better when spoken to; the voice has not to be much raised. Has tried to imitate the voices of the children singing, but can only attempt to utte " oh, I say." Tried to say "lady" when a visitor came.

23rd.-Hears the knocks at the door. Air enters tympanic cavity with a drier sound; left membrana tympani fibrouslooking; a bloodvessel crosses it midway down behind manubrium; cone of light imperfect.

24th.-Drier sound with nasal bag. She pointed up to the sky when it was thundering to-day; had never noticed it before.

25th.-Tried to say "flower" when the word was loudly uttered to her.

28th.-Hears them speak in a low tone, and hears light knocks at the door.

3lst.-Heard thunder again, though it was not so loud frequently hears passing vehicles; tries to say "Put that down" when the words are spoken to her with moderate loudness.

Sept. 3rd. - Can hear if called when she is out of the room; says "ake" when I say " cake"; hears her playmates 